
\title{
is Research Suare \\ Validating HIRA-TAN for the molecular diagnosis of chronic suppurative otitis media
}

\author{
Dina Alia \\ Jichi lka Daigaku \\ Ferry Dwi Kurniawan ( $\nabla$ d1630@jichi.ac.jp ) \\ Jichi Medical University https://orcid.org/0000-0003-1212-6420 \\ Azwar Ridwan \\ Universitas Syiah Kuala \\ Wilda Mahdani \\ Universitas Syiah Kuala \\ Koichi Hagiwara \\ Jichi lka Daigaku
}

\section{Research note}

Keywords: suppurative otitis media, pathogen, real-time polymerase chain reaction, molecular diagnostics

Posted Date: September 24th, 2019

DOI: https://doi.org/10.21203/rs.2.14857/v1

License: (c) (i) This work is licensed under a Creative Commons Attribution 4.0 International License.

Read Full License 


\section{Abstract}

Objective : Pathogen identification is critical for antibiotic selection in suppurative otitis media. However, causative pathogen determination from suppurative specimens of the middle ear is challenging. The current study investigated the utility of HIRA-TAN defining the causative pathogen in chronic suppurative otitis media based on the cycle-threshold difference between the targeted pathogen and the single-copy human gene by quantitative PCR.

Results : Thirty-nine patients were recruited to the study, and the otorrhea was swab-collected and subjected to bacterial culture and HIRA-TAN which the cycle-threshold cut-off was determined using receiver operating characteristic curves. A total of $35.9 \%$ of samples were positive for bacterial culture; $P$. aeruginosa , K. pneumoniae, P. mirabilis, and M. morganii. While B. fragilis , A. baumanii , M. catarrhalis , and $\mathrm{E}$. coli were not identified by culture though high cycle-threshold values were obtained suggesting the inability of the culture system in detecting some pathogens. Our results indicate that HIRA-TAN is a potential diagnostic tool in suppurative otitis media and warrant more extensive studies.

Keywords: suppurative otitis media, pathogen, real-time polymerase chain reaction, molecular diagnostics

\section{Introduction}

Chronic suppurative otitis media (CSOM) is a persistent infection of the middle ear associated with a perforated tympanic membrane resulting in ear discharge for more than six weeks [1]. The morbidity in children is high in many countries including Indonesia. Affected children often lose hearing capability [2], resulting in poor academic performances [1]. Early diagnosis, eradication of infection, and prevention of recurrence are warranted for effective control.

Identification of the causative pathogens is essential for treatment strategies. However, accurate identification is challenging owing to colonizing bacterial contamination and bacterial culture difficulty from suppurative specimens. Consequently, antibiotics misuse and disease recurrence are frequent $[3,4]$ and additional techniques that can exclude the colonizing pathogens is required to define the causative pathogens. Human cell-controlled identification of the respiratory agent (HIRA-TAN method) is a technique that utilizes the battlefield hypothesis [5] for accurate pathogen identification. According to the battlefield hypothesis, the ratio of causative pathogen cells to human cells in a purulent sample is considered as an indicator for the discrimination of the causative pathogen from the colonizing organisms. A pathogen with a high ratio indicates a higher number of pathogen cells to inflammatory cells, which suggests that it is likely to be the causative pathogen. HIRA-TAN has been successfully used to differentiate the causative pathogen from commensal organisms in the untreated CommunityAcquired Pneumonia (CAP) and progressive course pneumonia [6, 7].

CSOM is a chronic inflammation where the number of pathogen cells and human inflammatory cells are in a balance-neither the pathogen overwhelms the inflammatory cells, nor the inflammatory cells dominate the pathogens. Therefore, the ratio of pathogen cells to human cells would be in a specific 
range, and the HIRA-TAN approach might be applicable for CSOM diagnosis. However, the technique should be validated before adopting it to the clinic. In the current study, we examined the utility of the HIRA-TAN method for pathogen identification that cause CSOM.

\section{Main Text \\ Methods}

\section{Specimen collection}

Samples were collected at the Dr. Zainoel Abidin Hospital between December 2016 and January 2017. The study recruited adult and children participants who had persistent and recurrent mucopurulent otorrhea for more than two months with a perforated tympanic membrane(s). Participants under 16 years old were seated in the examination chair accompanied by the parents. The ear canal was cleansed, and the otorrhea was swab-collected under otoscopic guidance. The samples were processed for bacterial culture and HIRA-TAN assay. Audiometry was performed to confirm hearing impairment.

\section{HIRA-TAN method}

Primers and fluorescent probes (Supplementary Table 1) were designed for common pathogens reported such as Pseudomonas aeruginosa, Staphylococcus aureus, Streptococcus pneumoniae, Haemophilus influenzae, Moraxella catarrhalis, Escherichia coli, Klebsiella spp., Bacteroides spp., and Proteus spp. [8, 9] based on the genome sequences obtained from the National Centre for Biotechnology Information (NCBI) nucleotide database. A pair of primer and a fluorescent-labeled probe reflect a target detection. Sixteen targets were able differentiate five genera (Pseudomonas spp., Enterobacter spp., Staphylococcus spp., Streptococcus spp., and Proteus spp.), nine species (P. aeruginosa, E. coli, S. aureus, S. pneumoniae, K. pneumoniae, A. baumanii, $H$. influenza, M. catarrhalis, and $B$. fragilis),, a methicillin resistance gene $(m e c A)$," and a human tumor necrosis factor gene (TNF).. DNA extraction and real time PCR setting (Supplementary Table 2) were similar performed from previous study.[7]

\section{Semi-quantitative determination of pathogen and human cell numbers}

The copy number of a pathogen-specific gene represents the number of bacterial cells and a humanspecific gene represents the number of human cells. Thus, the number ratio of pathogen cells to human cells, $\Delta$ CtPathogen was determined using the following equation. 
$\Delta C t_{\text {Pathogen }}=-\left(C t_{\text {Pathogen }}-C t_{\text {Human }}\right)$

$$
=\log \left(\frac{\text { Number of pathogen cells }}{\text { Number of human cells }}\right)
$$

Where, CtPathogen is the cycle-threshold for the pathogen-specific gene and CtHuman is the cyclethreshold for the human-specific gene. Based on the battlefield hypothesis, pathogens with a $\Delta$ CtPathogen over the cut-off value overpower the human inflammatory cells in numbers thus the likely causative pathogens can be deduced.

In the current study, the $T N F$ gene was used as a human-specific gene and the $\triangle$ CtPathogen cut-off value was determined by a receiver operating characteristic (ROC) curve analysis. Cycle-threshold (Ct) values were obtained from 4-fold serial dilutions of genomic DNA. The Ct values were plotted against the log of the copy number of genomic DNA, and a linear regression equation was obtained.

\section{Statistical analyses}

All analyses were performed using EZR on R 3.3.1 and R commander 2.3-0 [10].

\section{Results}

\section{Clinical characteristics}

Thirty-nine patients (mean age $=32$ years) $(1.7-62)$ were enrolled in the study. Twenty-nine were adults (> 20 -year-old), and 10 were children. The symptoms reported were ear discharge (100\%), hearing problems (69.2\%), ear pain (61.5\%), ear itching (64.1\%), and fever (33.3\%). Adults (24/29 patients) had a significantly higher rate of hearing impairment than children (3/10 patients; Table 1$)$.

\section{HIRA-TAN}

For determining whether HIRA-TAN can be used to identify the causative pathogen, we performed a realtime PCR analysis for all 16 targets ( 15 targets were for pathogen genes and one for the human gene) and plotted the $\Delta$ CtPathogen values (Figure 1). Samples were also subjected to bacterial culture, and positive results were obtained in 14 patients (36\%). Cultured bacteria included $P$. aeruginosa, $K$. pneumoniae, P. mirabilis, and M. morganii (Black dots in Figure 1; Supplementary Table 3). Samples positive for culture (black dots) showed a high $\Delta$ CtPathogen. However, some samples negative for culture (white dots) showed similar $\Delta$ CtPathogenvalues. These samples were considered as false negative culture results or samples in which most of the bacteria are not alive. We performed the ROC 
curve analysis in four pathogens that were detected by culture in at least one sample for determining the $\Delta \mathrm{CtPathogen} \mathrm{cut-offfor}$ identifying the causative pathogen (Figure 1, red lines). The $\Delta \mathrm{CtPathogen} \mathrm{cut-}$ off,sensitivity, and specificity values were as follows: P. aeruginosa: 3.33 (90\%, 100\%), K. pneumoniae: $1.71(85 \%, 100 \%)$, and Proteus sp: 8.29 (90\%, 100\%) (Supplementary Figure 1). The $\Delta$ CtPathogen cut-off for $B$. fragilis, A. baumanii, M. catarrhalis, and E. coli could not be determined, as they were not detected by culture. The results indicated that HIRA-TAN picked up pathogens that are likely to be the causative pathogen among the culture positives.

\section{HIRA-TAN using copy number}

Real-time PCR was able to determine the copy number of the targets in the samples semi-quantitatively. Therefore, HIRA-TAN may be performed to determine copy numbers both human and pathogen genome. Using the human genomic DNA and the genomic DNA from 10 pathogens, we plotted a standard curve and performed HIRA-TAN analysis (Supplementary Figure 2). The results were not conclusive-culturepositive samples were not well discriminated from the culture-negative samples.

\section{Discussion}

Pathogens that were identified by bacterial culture showed a higher $\Delta \mathrm{CtPathogen}$ value, suggesting that HIRA-TAN may be used for causative pathogen identification. The patient age in the study population showed a broad distribution, consistent with the reports that CSOM is a disease involving all age groups $[8,9]$. The rate of hearing impairment was higher in adults than in children. Repeated episodes of infection and inadequate treatment during childhood have been associated with acquired hearing loss $[11,12]$ Early and complete eradication of infection is critical for managing CSOM.

Our results reported that the most frequently isolated bacteria from CSOM samples are $P$. aeruginosa, Proteus spp., and Klebsiella spp. are in line from earlier studies [13, 14].

The difference with other reports may be due to the difference in the study population or geography [15]. Our results are consistent with a previous study that reported that only a limited number of bacterial species cause CSOM. Accordingly, many hospital laboratories screen only a small number of species during routine tests[16]. Considering the number of the candidate species and consistency of our results with the previous reports, HIRA-TAN may be an attractive approach for identifying the causative pathogen of CSOM.

B. fragilis, A. baumanii, M. catarrhalis, and E. coli showed high $\Delta$ CtPathogen values. Nevertheless, they were not detected by bacterial culture, and the ROC curve analysis could not be performed. The results of PCR indicate that numerous bacteria are present in the specimen. It may be possible that many bacteria were nonviable. It is known that DNA from nonviable bacteria does not persist for more than one day in middle ear effusions [17]. Furthermore, the culture-sterile middle ear effusion has been suggested to be viable and metabolically active [18]. Therefore, a positive HIRA-TAN result likely indicates viable but not 
culturable bacteria in the sample, which may be included as therapeutic targets. For improving pathogen identification in CSOM, HIRA-TAN method may be alternative in addition to culture. Further investigation is required to be implemented and the current study is a reasonable beginning.

\section{Limitations}

- We recognized that the sample was small thus statistical analysis may be inadequate requiring larger cohort to verify the sensitivity and specificity.

- The culture-positive samples were not well discriminated from the culture-negative samples requiring further investigation of the non-viability issue.

- The pathogens above the $\left[\Delta \mathrm{Ct} \rrbracket \_P a t h o g e n\right.$ cut-off and those that were culture-negative might also be causative pathogens and requires further verification.

\section{Abbreviations}

CSOM: chronic suppurative otitis media; HIRA-TAN: human cell-controlled identification of the respiratory agent from "TAN" (sputum in Japanese); CAP: community-acquired pneumonia; MRSA: methicillinresistant S. aureus; NCBI: national centre for biotechnology information Ct: cycle threshold; ROC: receiver operating characteristic

\section{Declarations}

\section{Ethics approval and consent to participate}

The study was approved by both institutional review boards of Dr. Zainoel Abidin Hospital and Universitas Syiah Kuala (approval number: 06/KE/FK/2016), and Jichi Medical University (approval number: 17-123). The signed informed consent was obtained from the study participants. Informed consent was sought from the parents of all children participating in this study.

\section{Consent for publication}

Not applicable

\section{Availability of data and materials}

The datasets used and/or analyzed during the current study are available from the corresponding author on reasonable request.

\section{Competing interests}


The authors declare that they have no competing interests.

\section{Funding}

This research was supported by Jichi Medical University which had no role in study design, data collection and analysis, and manuscript preparation.

\section{Authors' contribution}

DA designed the study, performed the experiment, wrote the manuscript. FDK assisted the experiment, analyzed data, and edited the manuscript. AR performed the clinical examination and data collection. WM performed the microbiology assay and data collection. KH conceptualized the study, obtained the funding, and assisted with the drafting, editing, and reviewing the manuscript. All authors read and approved the final manuscript.

\section{Acknowledgements}

We thank Megumi Higo, Akemi Okumura, and Yuka Yoshino for assisting the administration. We thank Jichi Medical University for financing the research. We also appreciate the support from Universitas Syiah Kuala and dr. Zainoel Abidin Hospital staffs.

\section{Authors' information}

\section{Affiliation}

${ }^{1}$ Comprehensive Medicine I, Saitama Medical Centre, Jichi Medical University, Saitama, Japan; ${ }^{2}$ Department of Ear, Nose and Throat, Faculty of Medicine, dr. Zainoel Abidin Hospital, Universitas Syiah Kuala, Banda Aceh, Indonesia; ${ }^{3}$ Department of Microbiology, dr. Zainoel Abidin Hospital, Universitas Syiah Kuala, Banda Aceh, Indonesia; 4Department of Respiratory Medicine Department, Saitama Medical Center, Jichi Medical University, Saitama, Japan

\section{References}

1.Khairi Md Daud M, Noor RM, Rahman NA, Sidek DS, Mohamad A. The effect of mild hearing loss on academic performance in primary school children. Int J Pediatr Otorhinolaryngol 2010;74(1):67-70.

2.Anggraeni R, Hartanto WW, Djelantik B, Ghanie A, Utama DS, Setiawan EP, et al. Otitis media in Indonesian urban and rural school children. Pediatr Infect Dis J 2014;33(10):1010-5. 
3.Mittal R, Lisi CV, Gerring R, Mittal J, Mathee K, Narasimhan G, et al. Current concepts in the pathogenesis and treatment of chronic suppurative otitis media. Journal of medical microbiology 2015;64(10):1103-16.

4.Argaw-Denboba A, Abejew AA, Mekonnen AG. Antibiotic-resistant bacteria are major threats of otitis media in Wollo area, northeastern Ethiopia: A ten-year retrospective analysis. Int J Microbiol 2016;2016:8724671.

5. Hirama T, Yamaguchi T, Miyazawa H, Tanaka T, Hashikita G, Kishi E, et al. Prediction of the pathogens that are the cause of pneumonia by the battlefield hypothesis. PLoS One 2011;6(9):e24474.

6.Hirama T, Minezaki S, Yamaguchi T, Kishi E, Kodama K, Egashira H, et al. HIRA-TAN: a real-time PCRbased system for the rapid identification of causative agents in pneumonia. Respir Med 2014;108(2):395-404.

7.Kurniawan FD, Alia D, Priyanto H, Mahdani W, Hagiwara K. HIRA-TAN detects pathogens of pneumonia with a progressive course despite antibiotic treatment. Respir Investig 2019;57(4):337-44.

8.DeAntonio R, Yarzabal JP, Cruz JP, Schmidt JE, Kleijnen J. Epidemiology of otitis media in children from developing countries: A systematic review. Int J Pediatr Otorhinolaryngol 2016;85:65-74.

9.Mahadevan M, Navarro-Locsin G, Tan HK, Yamanaka N, Sonsuwan N, Wang PC, et al. A review of the burden of disease due to otitis media in the Asia-Pacific. Int J Pediatr Otorhinolaryngol 2012;76(5):62335 .

10.Kanda Y. Investigation of the freely available easy-to-use software 'EZR' for medical statistics. Bone Marrow Transplant 2013;48(3):452-8.

11.Yiengprugsawan V, Hogan A, Strazdins L. Longitudinal analysis of ear infection and hearing impairment: findings from 6-year prospective cohorts of Australian children. BMC Pediatr 2013;13(13):28.

12.Aarhus L, Tambs K, Kvestad E, Engdahl B. Childhood Otitis Media: A cohort study with 30-year followup of hearing (The HUNT Study). Ear Hear 2015;36(3):302-8.

13.Yeo SG, Park DC, Hong SM, Cha Cl, Kim MG. Bacteriology of chronic suppurative otitis media-a multicenter study. Acta Otolaryngol 2007;127(10):1062-7.

14.Lee SK, Lee MS, Jung SY, Byun JY, Park MS, Yeo SG. Antimicrobial resistance of Pseudomonas aeruginosa from otorrhea of chronic suppurative otitis media patients. Otolaryngol Head Neck Surg 2010;143(4):500-5.

15.Prakash R, Juyal D, Negi V, Pal S, Adekhandi S, Sharma M, et al. Microbiology of chronic suppurative otitis media in a tertiary care setup of Uttarakhand state, India. North Am J Med Sci 2013;5(4):282-7. 
16.Neeff M, Biswas K, Hoggard M, Taylor MW, Douglas R. Molecular microbiological profile of chronic suppurative otitis media. J Clin Microbiol 2016;54(10):2538-46.

17.Post JC, Aul JJ, White GJ, Wadowsky RM, Zavoral T, Tabari R, et al. PCR-based detection of bacterial DNA after antimicrobial treatment is indicative of persistent, viable bacteria in the chinchilla model of otitis media. Am J Otolaryngol 1996;17(2):106-11.

18.Rayner MG, Zhang Y, Gorry MC, Chen Y, Post JC, Ehrlich GD. Evidence of bacterial metabolic activity in culture-negative otitis media with effusion. JAMA 1998;279(4):296-9.

\section{Tables}

Table 1. Clinical characteristics

\begin{tabular}{lcc}
\hline \multicolumn{1}{c}{ Signs \& symptoms } & Children (\%) & Adult (\%) \\
\hline Ear discharge & $10(100)$ & $29(100)$ \\
Ear pain & $4(40)$ & $20(68.9)$ \\
Itching & $7(70)$ & $18(62)$ \\
Fever & $3(30)$ & $10(34.4)$ \\
Hearing impairment* & $3(30)$ & $24(82.7)$ \\
\hline
\end{tabular}

\section{* Fisher's exact test, $\mathrm{p}<0.005$}

\section{Figures}

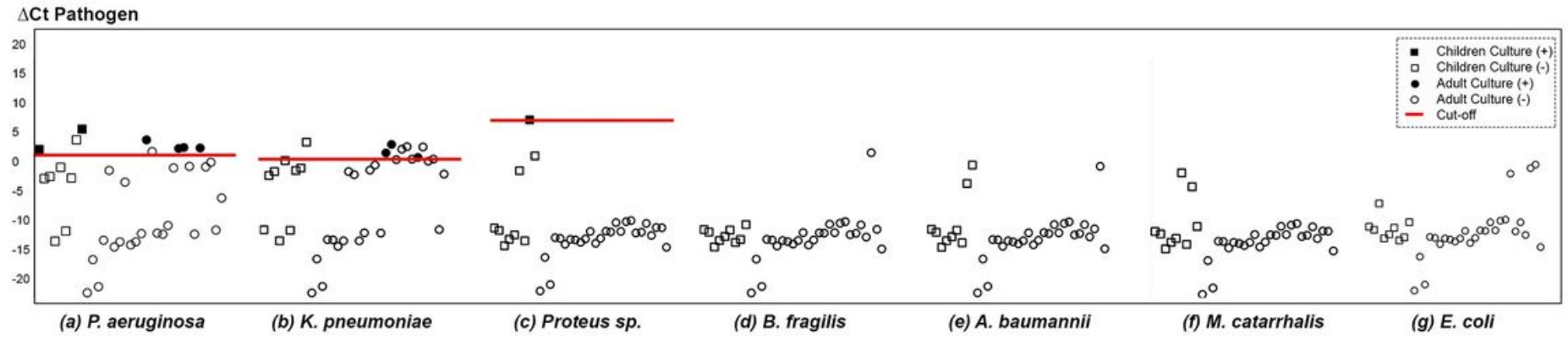

\section{Figure 1}


HIRA-TAN test results The $\Delta[\mathrm{Ct} \rrbracket]$ Pathogen of bacterial detection by the HIRA-TAN method. The red line indicates the cut-offs. (a) P. aeruginosa, (b) K. pneumoniae, (c) Proteus sp., (d) B. fragilis, (e) A. baumanii, (f) M. catarrhalis, and (g) E. coli. Bacteria a-c were isolated from bacterial cultures, and the cut-off values were calculated using ROC analysis, while $\mathrm{d}-\mathrm{g}$ were not isolated, and the ROC cut-off values were not calculated. Ct above 30 was eliminated.

\section{Supplementary Files}

This is a list of supplementary files associated with this preprint. Click to download.

- 20190829ROCanalysis80mmSupplFig1.tif

- SupplementaryTable123.docx

- 20190829CopyNumber160mmSupplFig2.tif 